\title{
Have Technology Specific Measures for the UK Electricity Market Reform Gone Far Enough?
}

\author{
Francine Baker
}

\begin{abstract}
The United Kingdom Government recently published a package of measures which would support investment in low-carbon technologies in the years up to 2020.

It has also taken account of the highly uncertain investment conditions relating to the period beyond 2020, which threaten to undermine the 2014 Electricity Market Reform measures and deliver bad value. The CFD scheme under the Energy Act 2013 should provide a stable revenue level which should, in turn, reduce investment risks and financing costs, and so drive innovation and development of low-carbon technologies. The scheme can also cap the support costs for consumers when electricity prices are high. Concerns about the impact of CFD allocation policies on the solar industry can be addressed. This paper indicates that there is a clear benefit in committing to invest in low-carbon generation technologies to 2020, and beyond to the 2030s.
\end{abstract}

The Government should state clearly that it intends to support investments in low-carbon technologies through the 2020s.

Index Terms - Renewable obligation, energy solar power, CFD.

\section{INTRODUCTION}

There has been an ongoing major reform of the electricity market in the United Kingdom since July 2011 culminating in the recent Electricity Market Reform (General) Regulations 2014 (EMR). These are the first regulations to be made using the powers in Chapter 2 of Part 2 of the Energy Act 2013 (c. 32). The EMR is the Government's response to challenges facing the electricity sector:

- The UK faces very rapid closure of existing capacity as older, more polluting plant go offline;

- The need to transform our generation mix to respond to the challenge of climate change and meet our legally-binding carbon reduction and renewable targets; and,

- The expectation that electricity demand will continue to increase over the coming decades [1].

The Government has developed a number of measures to ensure these objectives can be carried out. However this paper only has the scope to focus on a discussion of one of two technology specific measures: that is, Contract for Difference (CFD). It will consider what impact and contribution it will make to reform the electricity market and to assist

Manuscript received January 5, 2014; revised May 12, 2015. This work was supported in part by Wolfson College, Oxford and by the Open University, UK

Francine Baker is with Wolfson College Oxford, Open University, UK, she is also with Oxford Brookes University, UK (e-mail: fbaker@brookes.ac.uk, f.m.baker@open.ac.uk). technological developments, focusing on the solar industry.

\section{BACKGROUND}

Electricity Reform may be said to have started back in 1989 when the Electricity Act 1989 enabled the Secretary of State to impose an obligation on suppliers to supply a specified proportion of their electricity from renewable energy sources. Much legislation has developed since then. Under the Climate Change Act 2008, the UK made a long term national commitment to reduce its emissions by 80 per cent from its 1990 levels by 2050 . The UK is also committed to a legally binding target of sourcing 15 per cent of its final energy consumption (including electricity, heat and transport sectors) from renewable sources under the Renewable Energy Directive (Directive 2009/28/EC). In addition the UK must comply with The Energy Efficiency Directive, approved in 2012, which repeals the Cogeneration Directive (2004/8/EC) and the Energy End-Use Efficiency and Energy Services Directive (2006/32/EC). It fills the gap between existing framework Directives and national/international measures on energy efficiency and the 2020 EU target for energy savings. It covers all sectors except transport, and includes, for the first time in an "energy efficiency" directive, measures for supply side efficiency. [2] In order to meet its legal obligations, around 30 per cent of the UK's electricity and 12 per cent of the UK's heating will have to come from renewable sources by 2020 . Some progress has been made towards the UK's 15 per cent target, however only 3.8 per cent of energy consumption in 2011 came from RES [3].

\section{RECENT REFORM}

A major reform to the energy market came about through the Energy Act 2013 (the Act). [4] It provides a framework to deliver the United Kingdom Government's Electricity Market Reform (EMR). [5] Its objective is to ensure the supply and decarbonisation of the power sector at an affordable cost to consumers. This legal framework delivers feed-in tariffs based on contracts for differences (CFDs) and the capacity market for wholesale electricity. The Act also provides for the setting of a decarbonisation range for the UK and the establishment of a statutory Office for Nuclear Regulation. The 2014 EMR objectives aim to maintain security of supply, ensuring that the lights will stay on; make progress towards our decarbonisation and renewables targets; and ensure that consumers pay a fair price for low carbon electricity [6].

\section{A. Renewable Obligations}

The operators of a Renewable Obligations (RO) accredited 
biomass co-firing stations or unit(s) will be able to apply for a Contract for Difference (CFD). The aim is to encourage full biomass conversion as a transitional technology, and replace to RO's with CFD's [7].

The renewables obligation (RO) is a market-based mechanism which came into effect on 1st April 2002. It replaced the previous non fossil fuel obligation (NFFO). [8] The RO has been the main financial support mechanism used by the UK government to encourage the development of large-scale renewable electricity generation projects. Under the renewables obligation order 2009 (as amended) (RO Order) the renewables obligation (Scotland) order 2009 (as amended) (ROS Order) and the renewables obligation order (Northern Ireland) 2009 (as amended) (NIRO order ) certain renewable source technologies have been eligible to receive support) [9].

This has involved a system of green certificates (ROCs) to support the deployment of renewable energy capacity. Under this support system, accredited generators have been allocated green certificates (renewable obligation certificates (ROCs)) based on the net renewable electricity that is generated each month. Generating stations must first meet certain statutory criteria, including the fact that they have been commissioned, in order to be accredited under the Orders. Generators are issued renewable obligation certificates (ROCs) by an accredited renewable generating station. Once they have been accredited, they have to meet further criteria on a monthly basis if ROCs are to be issued. If accreditation has been granted and ROCs have subsequently been issued, the generator is responsible for transferring the certificates to a suitable party. ROCs can be sold directly or indirectly to suppliers who will redeem them against their Renewables Obligation. The renewable obligation created a market for ROCs and generators to derive revenue from the sale of ROCs to suppliers [10].

Licensed electricity suppliers have an obligation to source a proportion of the electricity they supply or pay a published buy-out price. The obligation is set at 15.8 per cent of the electricity supplied to consumers for $2012 / 2013$. It increased to 20.6 per cent in $2013 / 2014$. However, the RO is currently being phased out and will be replaced by CFD's from March 2017. RO's will still have the most significant effect on the price of industrial electricity to 2020, although the exact costs in 2020 will depend on how many renewable generators apply for RO support compared to CfD support during the transition period between the two schemes [11].

\section{B. Contract for Difference Scheme (CFD)}

The object of the CFD scheme seems to be to provide stable and certain revenues to electricity generators. It will also, cap the support costs for consumers when electricity prices are high. The scheme involves a private law contract between a low carbon electricity generator and the low carbon contracts company (LCCC). The LCCC is a private company, owned by the Department of Energy and Climate Change (DECC), which will manage the new contracts for difference (CFD) The act provides for generators to enter into CFDs with a CFD counterparty which is wholly owned by the government but will operate at arm's length from government. [12] Under the CFD arrangements, low-carbon generators will enter into long term contracts which are based on a fixed strike price. Assuming that generators can sell power in the wholesale energy market at the market reference price, the CFD mechanism compensates generators by paying the difference between the 'strike price- a price for electricity reflecting the cost of investing in a particular low carbon technology — and the 'reference price' — a measure of the average market price for electricity in the wholesale electricity market (calculated differently depending on whether the generator is intermittent or baseload). However, the downside is that if the market reference price is higher than the strike price, the CFD counterparty will require the generator to pay the difference back. It is however intended that a stable revenue level should, in turn, reduce investment risks and financing costs, and so drive innovation and development of low-carbon technologies [13].

CFDs are a leveraged product funded by a levy on all licensed electricity suppliers (the 'supplier obligation'). The new feed-in-tariffs with contracts for difference introduced in 2014 will eventually wholly replace the RO but generators have a choice between the RO and the new CFD scheme, until the RO closes to new capacity on April 1, 2017 [14].

The CFD scheme contributes to reform the market because CFD trading allows a position on the future value of an asset as to whether it will go up or down. The product is therefore very flexible, but it also requires a high level of risk management. Only a small deposit is needed for a much larger market exposure, and there are significant benefits and risks: the investment capital can go further, and this will assist technological developments, but you may also lose more than your initial deposit. It's important to remember that one is not physically trading in the underlying market. This means the company or organisation does not actually own any assets [15].

On April 9, 2014 the European Commission released the finalised Guidelines for environmental and energy projects (the "final Guidelines"). They remove the distinction between the treatment of "developed" and "less developed" technologies. However, this distinction remains in the UK Government's CFD allocation response as it broadly groups technologies into "established", or "Group 1", and "less established", or "Group 2"catagories. Some technologies sit outside these groups and there is a suggestion that Groups 3 and 4 may be added later to accommodate the relevant technologies in the form of "established" and "less established" technologies.

The unclassified technologies are listed under "other" (shown in Table I).

TABLE I: THREE GROUPS OF TECHNOLOGIES [16]

\begin{tabular}{|c|l|l|}
\hline Group 1 (Established) & $\begin{array}{l}\text { Group 2 (Less } \\
\text { Established) }\end{array}$ & \multicolumn{1}{|c|}{ Other } \\
\hline onshore wind & offshore wind & nuclear \\
larger than 5MW & wave & biomass conversion \\
solar p.v larger & tidal stream & CCS \\
than 5MW, & advanced & large hydro \\
waste with CHP & conversion & tidal \\
hydro projects & technology & Scottish island \\
which are greater & anaerobic digestion & onshore wind \\
than 5MW but less & dedicated biomass & \\
than 50MW & with CHP & \\
landfill gas & geothermal & \\
\hline
\end{tabular}


There may appear to be a discrepancy between the final Guidelines and the UK Government's CFD allocation response, but the key European objective of market integration is more vigorously pursued under the CFD, because of its early adoption of a competitive bidding process for "established" technologies as opposed to a "First-Come-First- Serve" approach. The UK Government has nevertheless confirmed that its approach is still in line with the final Guidelines [17].

Biomass conversions are entitled to compete for support as 'established technologies' under the new CFD regime, but the co-firing of biomass is not eligible for support under the CFD. So coal power stations that are converted to biomass, or where the level of co-firing alongside coal is to be increased, will no longer be guaranteed support under the Renewables Obligation (RO) before it ends in 2017. Biomass seems to have been isolated from the other "established" technologies in Group 1 because the long-term fuel supply costs required for biomass conversion indicates that the price of fuel would undermine their ability to bid competitively at auction for CFDs. It would not be able to compete with other types of established technologies. This isolation is consistent with the European Guidelines where an exception is made for State aid for biomass after plant depreciation so that the fuel costs do not result in a reversion to cheaper fossil fuels [18].

In July 2014, the Department of Energy and Climate Change (DECC) announced the availability of $£ 205 \mathrm{~m}$ worth of CFD contracts in the first phase of the scheme, with $£ 155 \mathrm{~m}$ to be awarded to less mature clean technology projects, such as offshore wind farms. The concern is that the latter amount will only enable the development of one mid-sized offshore wind farm, which is hardly in line with the government's ambitious offshore wind development plans at risk. DECC also announced that $£ 50 \mathrm{~m}$ is available at auction for those technologies that have been deemed mature. Solar has been placed in the mature technology pot, alongside onshore wind, energy from waste with CHP, Hydro, landfill gas and sewage gas. All these technologies will need to compete by bidding for support contracts at an auction designed to identify those that can generate clean power at the lowest cost [19].

The government is removing all RO support for solar developments over 5MW from April 2015. This seems to be because the Department of Energy and Climate Change (DECC) failed to accurately model the current explosion in solar farm deployment and a high proportion of the Levy Control Framework (LCF) budget has been consumed by solar. DECC is concerned that the rapid growth of the UK solar industry, supported by the "demand-led" RO, will breach the Levy Control Framework (LCF) DECC's "updated assessment" found that "in the absence of intervention", up to $10 \mathrm{GW}$ of solar PV could deploy within this period, costing some $£ 400 \mathrm{~m}$ more than was allowed for in the EMR Delivery Plan and exceeding the LCF limits on the overall amount of money that the Treasury can spent on renewable energy subsidies. The unanswered question is why DECC has not allocated the onshore wind under spend to help support continued solar farm growth? When DECC first revealed that solar was going to be considered an 'established' technology it was argued that it wasn't ready yet to compete on price terms. DECC responded by stating that solar costs are falling so quickly that it will be competitive when CFDs are introduced. However, as can be seen from the table below, the industry has not had much time to prepare.

TABLE II: CFDs' NEXT STEPS [20]

\begin{tabular}{|l|l|}
\hline Planned Date & Implementation Date \\
\hline June 2014 & $\begin{array}{l}\text { The final CfD Allocation Framework } \\
\text { published }\end{array}$ \\
\hline July 2014 & $\begin{array}{l}\text { The indicative CfD budget to National } \\
\text { Grid for allocation to be published }\end{array}$ \\
\hline 12 September 2014 & $\begin{array}{l}\text { National Grid publishes information } \\
\text { on how to apply for a CfD }\end{array}$ \\
\hline 14 October 2014 & CFD applications can be made \\
\hline 26thNov - 3rd Dec & $\begin{array}{l}\text { CFD applicants put in sealed bids (if } \\
\text { competition is required }\end{array}$ \\
\hline Christmas Eve & $\begin{array}{l}\text { Ed Davey reviews National Grid's } \\
\text { proposed allocation and decides } \\
\text { whether to go with it }\end{array}$ \\
\hline $29^{\text {th } D e c-13 J a n ~ 2015 ~}$ & $\begin{array}{l}\text { The results of competitive bidding } \\
\text { announced and winners start receiving } \\
\text { their contracts }\end{array}$ \\
\hline $29^{\text {th } \text { April 2015 }}$ & $\begin{array}{l}\text { Earliest CFD generators can start } \\
\text { being paid }\end{array}$ \\
\hline
\end{tabular}

The first CFD applications were in October 2014. This left little time between June and October to for developers to digest the CFD scheme. Although there still seem to be number of policy blanks, DECC put out a further consultation which closed on 24 October 2014 which has resulted in a separate 3 month grace period (until 30 June 2015) for projects which are prevented from meeting the 31 March 2015 deadline only because they are not connected to the grid by that date [21].

\section{Solar Industry}

The solution for the solar industry seems to be for the sector switch to the CFD regime, because the auction-based allocation process may drive down the costs of subsidy. Solar projects must compete with onshore wind developers, but since they have until 31 March 2017 to achieve RO accreditation, solar projects may be successful in being allocated CFDs. The remaining difficulty for a number of solar players is that the CFD regime is complex and is therefore likely to favour larger organisations with the capacity to come to grips with it quickly. It is also a requirement of signing a $\mathrm{CFD}$ contract that the industry players shows significant financial commitment 12 months after signing the contract for all technologies. This is known as the Milestone Delivery Date (MDD). [22] This is useful as it should discourage speculative bidding for CfDs protects, and prevent the CFD budget being allocated to 'speculative' projects. It also allows the CFD Budget to be recycled to other viable projects that do not meet the MDD. Although, Solar Photovoltaic has been given the shortest commissioning window of just 3 months, there is the possibility of extensions for delays.

\section{SOME RECOMMENDATIONS}

Low carbon generators need more certainty about the timing of funding allocation rounds for the rest of this decade.

To assist this, the Milestone Delivery Date for solar PV projects should be adjusted to 6 months prior to commissioning because of the shorter lead times and actual 
spend profile of large-scale solar projects. This will give solar projects the flexibility afforded to other technologies.

The large scale solar industry can be supported by changing the budget management of the CFD mechanism to increase the budget cap for $2017 / 18$ and $2018 / 19$ to $£ 100 \mathrm{~m}$ for the first auction round, to ensure that projects get built in the next 2 years. After the next two years, solar should then be in a position to compete with the other technologies. These options will not add more to the LCF.

The supply chain can be stabilised if minimum levels of offshore wind deployment in the 2020s are ensured, but this is dependent on generators meeting cost targets [23].

2020 is fast approaching. The government needs to make a clear decision about the level of contribution that renewables will make to the overall energy mix beyond 2020 now. The longer the government delays in setting clear 2030 decarbonisation targets for the power sector the more difficult and more expensive it will be to achieve it.

\section{REFERENCES}

[1] Legislation.gov.uk. (2014). Explanatory memorandum to the electricity market reform (general) regulations. [Online]. Available: http://www.legislation.gov.uk/ukdsi/2014/9780111116791/pdfs/ukds iem_9780111116791_en.pdf

[2] European Council for Energy Efficient Economy. Policy areas, the energy efficiency directive. [Online]. Available: http://www.eceee.org/policy-areas/EE-directive

[3] P. Clark, "Industry doubts subsidy scheme will boost green energy (Budget 2013)," The Financial Times, p. 2, March 18, 2013.

[4] Legislation.gov.uk. The Energy Act 2013. [Online]. Available: http://www.legislation.gov.uk/ukpga/2013/32/contents/enacted/data.h tm

[5] GOV.UK. Maintaining UK energy security. Policy. [Online]. Available:

https://www.gov.uk/government/policies/maintaining-uk-energy-secu rity--2/supporting-pages/electricity-market-reform

[6] M. G. Pollitt and A. B. Haney, "Dismantling a competitive electricity sector: The UK's electricity market reform," The Electricity Journal, vol. 26, issue 10, pp. 8-15, 2013.

[7] P. E. Mason, L. I. Darvell, J. M. Jones, M. Pourkashanian, and A. Williams, "Single particle flame-combustion studies on solid biomass fuels," Fuel, vol. 151, pp. 21-301, July 2015

[8] I. Diaz-Rainey and J. K. Ashton, "Stuck between a ROC and a hard place? Barriers to the take up of green energy in the UK," Energy Policy, vol. 36, issue 8, pp. 3053-3961, August 2008.

[9] A. Brown. (October 2, 2014). Early closure of RO to >5MW solar PV projects confirmed. Dentons. [Online]. Available: http://www.lexology.com/library/detail.aspx?g=9e60cd62-12bc-4565 -bead-0ef1ae61cea4

[10] Ofgem. (2015). Renewables obligation (RO). [Online]. Available: https://www.ofgem.gov.uk/environmental-programmes/renewables-o bligation-ro
[11] G. Gürkan and R. Langestraat, "Modeling and analysis of renewable energy obligations and technology bandings in the UK electricity market," Energy Policy, vol. 70, pp. 85-95, 2014.

[12] N. Kozlov, "Contracts for difference: Risks faced by generators under the new renewables support scheme in the UK," Journal of World Energy Law and Business, vol. 7, no. 3, pp. 282-286, 2014.

[13] D. Bunn and T. Yusupov, "The progressive inefficiency of replacing renewable obligation certificates with contracts-for-differences in the UK electricity market," Energy Policy, vol. 82, pp. 298-309, July 2015.

[14] R. Fagiani, J. Barquín, and R. Hakvoort, "Risk-based assessment of the cost-efficiency and the effectivity of renewable energy support schemes: Certificate markets versus feed-in tariffs," Energy Policy, vol. 55, pp. 648-661, 2013

[15] S. Spiecker and C. Weber, "The future of the European electricity system and the impact of fluctuating renewable energy - A scenario analysis," Energy Policy, vol. 65, pp. 185-197, 2014.

[16] Department of Energy and Climate Change. (May 13, 2014). Electricity market reform: Allocation of contracts for difference, a government response on competitive allocation. [Online]. p. 4 https://www.gov.uk/government/uploads/system/uploads/attachment_ data/file/310272/competitive_allocation_government_response.pdf

[17] A. Campoccia, L. Dusonchet, E. Telaretti, G. Zizzo, "An analysis of feed in tariffs for solar PV in six representative countries of the European Union," Solar Energy, vol. 107, p. 530, Sept. 2014.

[18] T. Fischer, "Making the case for conversion to biomass," Renewable Energy Focus, vol. 15, issue 5, pp. 24-25, 2014.

[19] R. Tucker, "Reviews mixed on UK's 1st CfD auction," Renewable Energy Focus, vol. 16, issue 2, pp. 14-16, March-April 2015.

[20] P. Bennet. (May 14, 2014). CfDs and the ROC cliff face. Solar Power Portal - Editor's Blog. [Online]. Available: $\mathrm{http}: / /$ www.solarpowerportal.co.uk/editors_blog/cfds_and_the_roc_cl iff_face_2367

[21] M. Murphy and N. Jones, "DECC continues to shake up the electricity market," Monday Business Briefing, May 13, 2014.

[22] P. Higgins and A. Foley, "The evolution of offshore wind power in the United Kingdom," Renewable and Sustainable Energy Reviews, vol. 37, pp. 599-612, 2014

[23] G. Boyle and Godfrey, "UK offshore wind potential: How offshore wind could supply a quarter of UK electricity by 2024," Refocus, vol. 7, issue 4, pp. 26-29, 2006.

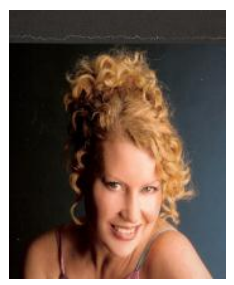

Francine Baker received her BA, LLB (Hons) degree in 1990, Queensland, Australia; got her MA $\left(1^{\text {st }} \mathrm{cl}\right.$. degree in 1996, Melbourne, Australia; then received her $\mathrm{PhD}$ degree in 2005, Cambridge and Melbourne.

She researches at Wolfson College, University of Oxford, England, and lectures for the Department of Real Estate and Construction, Oxford Brookes University, and for the Open University. She also has worked for many years for the College of Estate Management, Whiteknights, Reading, and more recently for the School of Construction Management and Engineering, University of Reading. Her research interests concern Sustainability issues for the Built Environment and Dispute Resolution.

Dr. Francine Baker is a solicitor of England and Wales (practising), and a barrister and solicitor of the High Court of Australia, ICIOB, MSCL, Worshipful Company of Constructors (Livery). 
Wind Energy 
